\title{
Constructal flow orientation in conjugate cooling channels with
}

\author{
internal heat generation
}

\author{
T. Bello-Ochende ${ }^{a^{*}}$, O.T. Olakoyejo ${ }^{a}$, J.P. Meyer ${ }^{a}$ A. Bejan ${ }^{b}$ and S. Lorente \\ ${ }^{a}$ Department of Mechanical and Aeronautical Engineering, University of Pretoria, Pretoria \\ Private Bag X20, Hatfield 0028, South Africa. \\ ${ }^{\mathrm{b}}$ Duke University, Department of Mechanical Engineering and Materials Science, Durham, \\ NC 27708-0300, USA \\ ${ }^{\mathrm{c}}$ Université de Toulouse, UPS, INSA, LMDC (Laboratoire Matériaux et Durabilité des \\ Constructions), 135, avenue de Rangueil,
}

\begin{abstract}
This paper presents the development of the three-dimensional flow architecture of conjugate cooling channels in forced convection with internal heat generation within the solid for an array of circular cooling channels with different flow orientation. Three flow orientations were studied: array of channels with parallel flow; array of channels in which the flow in every second row is in a counter direction with its neighbours, and flows in all the arrays of channels are in counter flow relative to each other. The geometric configurations were determined in such a way that the peak temperature was minimised subject to the constraint of fixed global volume of solid material. The degrees of freedom of the design were hydraulic diameter and channel to channel spacing. A gradient-based optimisation algorithm was applied to search for the best optimal geometric configurations that improve thermal performance by minimising thermal resistance for a wide range of dimensionless pressure differences. The effect of porosities, applied pressure difference, flow orientation and heat generation rate on the optimal
\end{abstract}

\footnotetext{
* Corresponding author. Tel.: +27 12 4203105; fax: +27 123625124

E-mail address: tunde.bello-ochende@up.ac.za
} 
hydraulic diameter and channel to channel spacing is reported. The results show that the effects of dimensionless pressure drop on minimum thermal resistance were consistent with those obtained in the open literature.

Keywords: Constructal design; Laminar flow; Forced convection; Peak temperature; Thermal resistance; Flow orientation

\section{Nomenclature}

$A_{c} \quad$ Cross-sectional area of the channel, $\mathrm{m}^{2}$

$A_{s} \quad$ Cross-sectional area of the structure, $\mathrm{m}^{2}$

Be Bejan number

$C_{P} \quad$ Specific heat at constant pressure, $\mathrm{J} / \mathrm{kg} \mathrm{K}$

$C F$ - 2 Counter - flow row

$C F-3 \quad$ Counter - flow channel

$d_{h} \quad$ Hydraulic diameter, $\mathrm{m}$

$H \quad$ Structure height, $\mathrm{m}$

$h \quad$ Elemental height, $\mathrm{m}$

$k \quad$ Thermal conductivity, W/mK

L Axial length, $\mathrm{m}$

$N \quad$ Number of channels

$n \quad$ Normal

$P \quad$ Pressure, $\mathrm{Pa}$

$P F-1 \quad$ Parallel - flow

$\operatorname{Pr} \quad$ Prandtl number

$q_{s}^{\prime \prime \prime} \quad$ Internal heat generation density, $\mathrm{W} / \mathrm{m}^{3}$ 
$R \quad$ Dimensionless Thermal resistance

$s \quad$ Channel spacing, $\mathrm{m}$

T Temperature, ${ }^{\circ} \mathrm{C}$

$\vec{u} \quad$ Velocity vector, $\mathrm{m} / \mathrm{s}$

$V \quad$ Global structure volume, $\mathrm{m}^{3}$

$v_{c} \quad$ Channel volume, $\mathrm{m}^{3}$

$v_{e l} \quad$ Elemental volume, $\mathrm{m}^{3}$

W $\quad$ Structure width, $\mathrm{m}$

w Elemental width, $\mathrm{m}$

$x, y, z \quad$ Cartesian coordinates, $\mathrm{m}$

Greek symbols

$\alpha \quad$ Thermal diffusivity, $\mathrm{m}^{2} / \mathrm{s}$

$\mu \quad$ Viscosity, $\mathrm{kg} / \mathrm{m} . \mathrm{s}$

$\rho \quad$ Density, $\mathrm{kg} / \mathrm{m}^{3}$

o Differential

$\infty \quad$ Far extreme end, free stream

$\phi \quad$ Porosity

$\Delta \quad$ Difference

$\nabla \quad$ Differential operator

$\gamma \quad$ Convergence criterion

Subscripts

$f \quad$ Fluid

$i \quad$ Mesh iteration index

in Inlet

$\max \quad$ Maximum, peak 


$\begin{array}{ll}\text { min } & \text { Minimum } \\ \text { opt } & \text { Optimum } \\ s & \text { Solid } \\ w & \text { Wall }\end{array}$

\section{Introduction}

Constructal theory and design $[1,2]$ have emerged as the evolutionary design philosophy for developing flow architectures that offer greater flow access and system performance. The approach is summarised by the constructal law [1, 2]: For a finite-size system to persist in time (to live), it must evolve in such a way that it provides easier access to the imposed (global) currents that flow through it. This philosophy has been applied to all the facets of flow system design, from biology and physics, to engineering and social organisation [3-20].

The application of this evolution design approach to the discovery of internal heat exchanger started with Bejan and Sciubba [3], who obtained the design rule for the spacing of an array of parallel plate to channels such that the heat transfer density of a volume filled with heat generating components is maximum. The spacings were determined by using method of the intersection of asymptotes.

In this paper our focus is on the first engineering application of constructal theory, which is the shape and structure for heat transfer and fluid flow [21-28]. The advantage of constructal law in the engineering field is that the flow architecture is not assumed in advance, but is the consequence of allowing the structure to morph [29]. The applications of this theory have been reviewed most recently by Bejan and Lorente [30]. The development of heat 
exchangers and multiscale architectural by constructal theory was also, reviewed by Reis [31] and Fan and Luo [32].

Yilmaz et al. [33] studied the optimum shape and dimensions for convective heat transfer of laminar flow at constant wall temperatures for ducts with parallel plate, circular, square and equilateral triangle geometries. Approximate equations were derived in the form of maximum dimensionless heat flux and optimum dimensionless hydraulic diameter in terms of the duct shape factors and the Prandlt number $(P r)$. Da Silva et al. [34], optimised the space allocation on a wall occupied by discrete heat sources with a given heat generation rate by forced convection using the method of constructal theory in order to minimise the temperature of the hot spot on the wall.

Bello-Ochende et al. [35] conducted a three-dimensional study of heat sinks and cooling channels with heat flux using scale analysis and the intersection of asymptotes method based on constructal theory to discover the design of cooling channels. Rocha et al. [36] and Biserni et al. [37] applied the same theory to the geometry of C-and H-shaped cavities respectively that intrude into a solid conducting wall in order to minimise the thermal resistance between the solid and the cavities. Muzychka [38] applied the methods to microtube heat sinks and heat exchangers for maximum heat transfer density by using a multiscale design approach. He was able to show that through the use of interstitial microtubes, the maximum heat transfer rate density for an array of circular tubes increased. Reis et al. [39] developed the internal configurations of parallel plate and cylindrical channels using contructal theory in order to understand the morphology of particle agglomeration and the design of air-cleaning devices.

Meyer's [40] on the work Bejan and Lorente [41] on constructal theory and also comments of other researchers [42-48] show that the constructal law's application in human life, nature and in all fields of educational design is a wide road to future advances. 
The growing constructal literatures focused on convective heat transfer analysis, but did not consider the effects of flow orientation. However, Ma et al. [49] experimentally investigated the flow resistance and forced convective heat transfer influence for flow orientation in a packed channel that experience heating at the bottom. Wang et al. [50], carried out numerical investigation to study the effect of orientation of heat sink on the thermal performance of a PCM-based cooling system. Other research on the effect of orientation can be found in Refs. [51-54].

This paper focuses on laminar forced convection heat transfer in a heat generating solid volume with three flow orientations in circular channels. The morphing flow space is subject to a finite global volume of solid material, which contains an array of circular cooling channels with a uniform internal heat generation. The objective is to document numerically the effect flow orientation on the flow resistance and forced convective heat transfer. This is done by building an elemental with which one can construct a larger construct body with several flow orientations. The three flow orientations are: an array of channels with parallel flow (PF-1); an array of channels in which flow of the every second row is in a counter flow with its neighbours (CF-2); and an array of channels in which flow in all the channels are counter flow to one another (CF-3).

\section{Computational model}

Figure 1 shows the three flow orientations. The system consists of a solid body of fixed global volume, $V$, which experience uniform volumetric heat generation $q_{s}^{\prime \prime \prime}$. The body is cooled by forcing a single-phase cooling fluid (water) from the left side through the parallel cooling channels. The flow is driven along the length $L$, of the circular channel with a fixed pressure difference $\Delta P$. An elemental volume shown in Fig. 2 consisting of four (4) cooling channels and the surrounding solid was accounted for by making use of symmetry and periodic 
boundary conditions. The heat transfer in the elemental volume is a conjugate problem, which combines heat conduction in the solid and the convection in the flowing fluid.

In Fig. 2, an elemental volume constraint $v_{e l}$ is composed of four circular cooling channels of equal hydraulic diameter $d_{h}$. The surrounding solid of thickness $s$ (equal spacing between all channels) means that:

$w=h$

The elemental volume is:

$v_{e l}=w^{2} L$

and the volume of a channel is:

$v_{c}=\frac{\pi}{4} d_{h}{ }^{2} L$

For a fixed length of the channel, the cross-sectional area of the structure is

$A_{s}=H W$

and this means that the number of channels in the structure arrangement is

$N=\frac{H W}{h w}$

The void fraction (or porosity) of the elemental structure is defined as:

$\phi=4 \frac{v_{c}}{v_{e l}}$

The objective is to find the channel hydraulic diameter, $d_{h}$, and the channel spacing, $s$, which offer minimum resistance to heat and flow. The analysis also focuses on the extreme limits of $0 \leq d_{h} \leq \infty$ and the extreme limits of $0 \leq s \leq \infty$.

The temperature distribution in the elemental volume was determined by solving the equations for the conservation of mass, momentum and energy numerically. A section of the 
discretised three-dimensional computational domain of the three flow orientation geometries is shown in Fig 3. The cooling fluid was water, which was forced through the cooling channels by a specified pressure difference, $\Delta P$, across the flow length of the structure. The fluid is assumed to be in single phase, steady and Newtonian with constant properties. Water as fluid is more promising than air, because air-cooling techniques are not likely to meet the challenge of high heat dissipation in electronic packages $[55,56]$. The governing differential equations used for the fluid flow and heat transfer analysis in the elemental volume of the structure are:

$\nabla \cdot \vec{u}=0$

$\rho(\vec{u} \cdot \nabla \vec{u})=-\nabla P+\mu \nabla^{2} \vec{u}$

$\rho_{f} C_{P f}(\vec{u} \cdot \nabla T)=k_{f} \nabla^{2} T$

The energy equation for the solid part of the elemental volume with internal heat generation can be written as:

$k_{S} \nabla^{2} T+q_{s}^{\prime \prime \prime}=0$

The continuity of the heat flux at the interface between the solid and the liquid is given as:

$\left.k_{S} \frac{\partial T}{\partial n}\right|_{w}=\left.k_{f} \frac{\partial T}{\partial n}\right|_{w}$

A no-slip boundary condition is specified for the fluid at the wall of the channel,

$\vec{u}=0$

At the inlet $(z=0)$,

$u_{x}=u_{y}=0$

$T=T_{\text {in }}$

$P=\frac{\alpha \mu B e}{L^{2}}+P_{\text {out }}$ 
where $B e$, is the dimensionless pressure difference defined in Refs. [57, 58].

$$
B e=\frac{\Delta P L^{2}}{\mu \alpha_{f}}
$$

where

$$
\alpha_{f}=\frac{k_{f}}{\rho_{f} C_{P f}}
$$

At the outlet $(z=L)$, the pressure is prescribed as zero normal stress

$$
P_{\text {out }}=1 \text { atm }
$$

For the PF-1 configuration, the top, bottom, left and right boundaries of the domain correspond to symmetry boundary conditions. For CF-2 and CF-3, the top, bottom, left and right side of the solid surfaces had spatially periodic thermal boundary conditions. The remaining outside walls and the plane of symmetry were modeled as adiabati, that is:

$$
\nabla T=0
$$

The measure of performance is the global thermal resistance, which could be expressed in a dimensionless form as:

$$
R=\frac{k_{f}\left(T_{\max }-T_{i n}\right)_{\min }}{q_{S}^{\prime \prime \prime} L^{2}}
$$

and it is a function of the optimised design variables and the peak temperature.

$$
R=f\left(d_{h}, s, v_{e l}, T_{\max }, \text { flow orientation }\right)
$$

The inverse of $R$ is the global thermal conductance.

\section{Numerical procedure and grid analysis}

The simulation work began by fixing the channel length, pressure difference, porosity, and heat generation rate, and varying the geometry and flow orientation in order to identify the configuration decreases the peak temperature. The numerical solution of the continuity, 
momentum and energy Eqs. (7) - (11) along with the boundary conditions (12) - (20) was obtained by using a three-dimensional commercial package Fluent ${ }^{\mathrm{TM}}$ [59], which employs a finite volume method. The details of the method are explained by Patankar [60]. Fluent ${ }^{\mathrm{TM}}$ was coupled with the geometry and mesh generation package Gambit [61] using MATLAB [62] to allow the automation and running of the simulation process. The computational domain was discretised using hexahedral/wedge elements. A second-order upwind scheme was used to discretise the combined convection and diffusion terms in the momentum and energy equations. The SIMPLE algorithm was then employed to solve the coupled pressure-velocity fields of the transport equations. A flow chart representing the numerical procedure is shown in Figure 4. After the simulation had converged, an output file was obtained containing all the necessary simulation data and results for the post-processing and analysis. The solution is assumed to have converged when the normalised residuals of the mass and momentum equations fall below $10^{-6}$ and while the residual convergence of the energy equation was set to less than $10^{-10}$. The number of grid cells used for the simulations varied for different elemental volume and porosities. Grid independence tests for several mesh refinements were carried out to ensure the accuracy of the numerical results. The convergence criterion for the overall thermal resistance as the quantity monitored was:

$\gamma=\frac{\left|\left(T_{\max }\right)_{i}-\left(T_{\max }\right)_{i-1}\right|}{\left|\left(T_{\max }\right)_{i}\right|} \leq 0.01$

where $i$ is the mesh iteration index. The mesh was more refined as $i$ increases. The $i-1$ mesh was selected as a converged mesh when the criterion (23) was satisfied.

To ensure accurate results, several grid independence tests were conducted until a mesh size with negligible changes in peak temperature was obtained. Tables 1 - 3 show the grid independence test for the PF-1, CF-2 and CF-3 configurations respectively with $v_{e l}=2.5 \mathrm{~mm}^{3}$ $\phi=0.2$ for $\Delta P=50 \mathrm{kPa}$. The number of cells were $20400,36186,61410$ and 162400 for 
the PF-1 orientation configuration. It is observed that almost identical results were predicted when 61410 and 162400 cells were used. Therefore, a further increase in the cell density beyond 61410 has a negligible effect on the numerical result. The number of cells were 39 960, 43 000, 61410 and 162400 for the both CF-2 and CF-3 configurations. Noteworthy is that almost identical convergence performance emerges when 61410 and 162400 cells were used. Therefore, a further increase in the cell density beyond 61410 has a negligible effect on the numerical result.

Table 1: Grid independence study for the PF-1 configuration with $v_{e l}=2.5 \mathrm{~mm}^{3} \quad \phi=0.2$ and $\Delta P=50 \mathrm{kPa}$

\begin{tabular}{cccc}
\hline Number of nodes & Number of cells & $T_{\max }$ & $\gamma=\frac{\left|\left(T_{\max }\right)_{i}-\left(T_{\max }\right)_{i-1}\right|}{\left|\left(T_{\max }\right)_{i}\right|}$ \\
\hline 31091 & 20400 & 27.77 & - \\
50318 & 36186 & 27.754 & 0.000577 \\
81644 & 61410 & 27.764 & 0.000216 \\
204783 & 162400 & 27.764 & 0.000144 \\
\hline
\end{tabular}

Table 2: Grid independence study for the CF-2 configuration with $v_{e l}=2.5 \mathrm{~mm}^{3} \phi=0.2$ and $\Delta P=50 \mathrm{kPa}$

\begin{tabular}{cccc}
\hline Number of nodes & Number of cells & $T_{\max }$ & $\gamma=\frac{\left|\left(T_{\max }\right)_{i}-\left(T_{\max }\right)_{i-1}\right|}{\left|\left(T_{\max }\right)_{i}\right|}$ \\
\hline 54109 & 39960 & 27.671 & - \\
59909 & 43000 & 27.670 & 0.00000325 \\
81644 & 61410 & 27.693 & 0.000827 \\
204783 & 162400 & 27.709 & 0.000577 \\
\hline
\end{tabular}


Table 3: Grid independence study for the CF-3 configuration with $v_{e l}=2.5 \mathrm{~mm}^{3} \phi=0.2$ and $\Delta P=50 \mathrm{kPa}$

\begin{tabular}{cccc}
\hline Number of nodes & Number of cells & $T_{\max }$ & $\gamma=\frac{\left|\left(T_{\max }\right)_{i}-\left(T_{\max }\right)_{i-1}\right|}{\left|\left(T_{\max }\right)_{i}\right|}$ \\
\hline 54109 & 39960 & 27.671 & - \\
59909 & 43000 & 27.672 & 0.00000361 \\
81644 & 61410 & 27.694 & 0.000794 \\
204783 & 162400 & 27.710 & 0.000577 \\
\hline
\end{tabular}

\section{Numerical results}

The elemental volume of the structure was varied in the range of $0.125 \mathrm{~mm}^{3}$ to $20 \mathrm{~mm}^{3}$, and the porosity range was between $0.1 \leq \phi \leq 0.3$. The length was fixed at $L=10 \mathrm{~mm}$, and the applied pressure differences was specified as $\Delta \mathrm{P}=50 \mathrm{kPa}$. The thermal conductivity of the solid structure (silicon) is $148 \mathrm{~W} / \mathrm{m} . \mathrm{K}$, and the internal heat generation within the solid was taken to be fixed as $100 \mathrm{~W} / \mathrm{cm}^{3}$. The thermo-physical properties of water [63] used in this study were for water at $300 \mathrm{~K}$ and the inlet water temperature was fixed at this temperature.

Figures 5 and 6 show the existence of an optimum hydraulic diameter and elemental volume size in which the peak temperature is minimised at any point in the channel for the square configuration studied. Figure 5 shows the peak temperature as a function of the dimensionless channel hydraulic diameter. It shows that there exists an optimal channel hydraulic diameter, which lies in the range $0.005 \leq d_{h} / L \leq 0.025$ and minimizes the peak temperature.

The elemental volume of the structure has a strong effect on the peak temperature as shown in Fig. 6. The minimum peak temperature is achieved when the elemental volume is in the range $0.5 \mathrm{~mm}^{3} \leq v_{e l} \leq 8 \mathrm{~mm}^{3}$. This indicates that the global peak temperature decreases as the design variables (hydraulic diameter and elemental volume) increase or the global peak temperature decreases as the design variables decrease until it gets to the optimal design 
values. Therefore, any increase or decrease in the design variable beyond the optimal values indicates that the working fluid is not properly engaged in the cooling process, which is detrimental to the global performance of the system.

The results show that the optimal arrangement of the elemental volume for the entire structure at this fixed pressure difference should be very small in order to achieve a better cooling. The results also show that the flow orientation has a strong influence on the convective heat transfer as the peak temperature is lower in the two counter-flow arrangements compare to their parallel-flow counterpart and the two counter-flow arrangements show almost the same performance. However, the peak temperature of the PF-2 orientation is slightly lower (if $d_{h} / L<$ 0.01) than that of PF-3 orientation. Figures 5 and 6 also show that porosity has a significant effect on the peak temperature. The best cooling occurs at the highest porosity. That is, as the porosity increases, the peak temperature decreases. Furthermore, when the porosity increases the flow direction has almost no impact on the results. This means that this research finds its application in low porosity designs.

\section{Mathematical optimisation}

In this section, we introduce an optimisation algorithm that will search and identify the optimal design variables at which the system will perform best. A numerical algorithm, Dynamic-Q [64], is employed and incorporated into the finite volume solver and grid (geometry

and mesh) generation package by using MATLAB as shown in Figure 4 for more efficient and better accuracy in determining the optimal performance.

The Dynamic-Q is a multidimensional and robust gradient-based optimisation algorithm, which does not require an explicit line search. The technique involves the application of a dynamic trajectory LFOPC optimisation algorithm to successive quadratic approximations of the actual problem [65]. The algorithm is also specifically designed to handle a constrained 
problem where the objective and constraint functions are expensive to evaluate. The details of the Dynamic-Q and applications can be found in Refs. [64-70].

\subsection{Design variable constraints}

The constraint ranges for the optimisation are:

$0.125 \mathrm{~mm}^{3} \leq v_{e l} \leq 20 \mathrm{~mm}^{3}$

$0.1 \leq \phi \leq 0.3$

$0 \leq w \leq L$

$0 \leq d_{h} \leq w$

$0 \leq s \leq w$

The design and optimisation technique involves the search for and identification of the best channel layout that minimises the peak temperature, $\mathrm{T}_{\max }$ such that the minimum thermal resistance between the fixed volume and the cooling fluid is obtained with the desired objectives function. The aspect ratio (external and internal), hydraulic diameter and the channel spacing and elemental volume were considered as design variables while the length of the channel was fixed. However, the cross-sectional shape of the elemental structure for the rectangular configuration is fixed but is allowed to morph. Also the internal architecture of the cooling channel is allowed to vary in aspect ratio, hydraulic diameter, channel spacing in horizontal and vertical direction. A number of numerical optimisations and calculations were carried out within the design constraint ranges given in (24) - (28) and the results are presented in the succeeding section in order to show the optimal behaviour of the entire system. The optimisation process was repeated for applied dimensionless pressure differences $(\mathrm{Be})$ that correspond to $\triangle P=10 \mathrm{kPa}$ to $\triangle P=50 \mathrm{kPa}$. 


\subsection{Effect of the applied pressure difference}

Figure 7 shows the effect of the minimised thermal resistance as a function of applied dimensionless pressure difference for the three flow orientations. The minimised thermal resistance decreases as the applied dimensionless pressure difference and porosity increase. The results also show that the flow orientation has a strong influence on the convective heat transfer. For a specified applied dimensionless pressure difference and porosity, the PC-2 and PC-3 orientations have better performances than the PF1 orientation. The PC-2 and PC-3 orientations have almost the same performance. However, the performance of the PC-2 orientation is better than the performance of the CF-3 orientation. Details of the results can be seen in Table 4.

Figures 8 and 9 show the behavior of the geometry with respect to the applied dimensionless pressure difference at different porosities for the three configurations. The optimal hydraulic diameter $d_{\text {hopt }}$ decreases as the dimensionless pressure difference increases. There exists an optimal geometry for each of the applied dimensionless pressure differences for the three configurations.

Table 4: The minimised global thermal resistance $R_{\min }$ of the three configurations,

\begin{tabular}{|c|c|c|c|c|c|c|c|c|c|}
\hline \multicolumn{10}{|c|}{$R_{\min } \times 10^{3}$} \\
\hline \multirow[b]{2}{*}{$B e$} & \multicolumn{3}{|c|}{$\phi=0.1$} & \multicolumn{3}{|c|}{$\phi=0.2$} & \multicolumn{3}{|c|}{$\phi=0.3$} \\
\hline & PF-1 & $\mathrm{CF}-2$ & CF-3 & PF-1 & CF-2 & CF-3 & PF-1 & CF-2 & CF-3 \\
\hline $3.47 \times 10^{9}$ & 0.36 & 0.33 & 0.33 & 0.17 & 0.15 & 0.15 & 0.1 & 0.092 & 0.092 \\
\hline $6.94 \times 10^{9}$ & 0.26 & 0.24 & 0.24 & 0.12 & 0.11 & 0.11 & 0.071 & 0.066 & 0.066 \\
\hline $1.39 \times 10^{10}$ & 0.19 & 0.17 & 0.17 & 0.086 & 0.077 & 0.077 & 0.051 & 0.047 & 0.047 \\
\hline $2.08 \times 10^{10}$ & 0.15 & 0.14 & 0.14 & 0.07 & 0.063 & 0.063 & 0.042 & 0.038 & 0.038 \\
\hline $2.77 \times 10^{10}$ & 0.13 & 0.12 & 0.12 & 0.061 & 0.055 & 0.055 & 0.036 & 0.033 & 0.033 \\
\hline
\end{tabular}




$\begin{array}{llllllllll}3.47 \times 10^{10} & 0.12 & 0.11 & 0.11 & 0.055 & 0.049 & 0.049 & 0.033 & 0.03 & 0.03\end{array}$

In Fig. 9 the optimal channel spacing $s_{\text {opt }}$ is sensitive to the performance of the system. It decreases as the dimensionless pressure differences increase and there exists a unique optimal spacing for each of the applied dimensionless pressure differences for the configurations. The optimised spacing $S_{\text {opt }}$ is directly proportional to the optimised hydraulic diameter $d_{h_{\text {opt }}}$. This is also due to the fact that the elemental volume is not fixed, but it is allowed to morph for a fixed porosity. These results are also in agreement with past research work [35, 69].

\section{Conclusions}

This paper documented the numerical search for geometric structures of conjugate cooling channels in forced convection with internal heat generation within the solid for an array of parallel cylindrical cooling channels with three flow orientations, PF-1, CF-2 and CF-3. The configurations were developed in such that the peak temperature was minimised subject to the constraint of fixed global volume. The results show that the resulting geometry is a function of the dimensionless pressure difference number. The minimised dimensionless thermal resistance is sensitive to flow orientations. For specified applied dimensionless pressure difference and porosity, the CF-2 and CF-3 orientations perform better than the PF-1 orientation. The CF-2 and CF-3 orientations perform almost the same.

The use of the optimisation algorithm coupled with a CFD package made the numerical results robust with respect to the selection of optima geometries, flow orientations of the flow channels and dimensionless pressure difference. Therefore, when designing the cooling structure of heat exchange equipment, the internal and external geometries of the structure, flow orientation and the pump power requirements are very important parameters to be 
considered in achieving efficient performance. Future work would be to add one degree of freedom in the system by allowing the tube to have different diameter for always the same porosity.

\section{Acknowledgements}

The funding obtained from the NRF, TESP, Stellenbosch University / University of Pretoria, SANERI/SANEDI, CSIR, EEDSM Hub and NAC is acknowledged and duly appreciated.

\section{References}

[1] A. Bejan, Advanced Engineering Thermodynamics, 2nd ed., Wiley, New York, 1997.

[2] A. Bejan, Shape and Structure from Engineering to Nature, Cambridge University Press, Cambridge, UK, 2000.

[3] A. Bejan, E. Sciubba, The optimal spacing of parallel plates cooled by forced convection, International Journal of Heat and Mass Transfer, 35 (1992) 3259-3264.

[4] A. Bejan, S. Lorente, L. Lee, Unifying constructal theory of tree roots, canopies and forests, J. Theor. Biol. 254 (2008) 529-540.

[5] T. Bello-Ochende, A. Bejan, Fitting the duct to the "body" of the Convective flow, I Int. J. Heat Mass Transfer 46 (2006) 1693-1701.

[6] H. Wang, W. Dai, A. Bejan, Optimal temperature distribution in a 3D triple-layered skin structure embedded with artery and vein vasculature and induced by electromagnetic radiation, Int. J. Heat Mass Transfer 50 (2007) 1843-1854.

[7] A. Bejan, V. Badescu, A. De Vos, A., Constructal theory of economics structure generation in space and time, Energy Convers. Manage. 41 (2000) 1429-1451.

[8] A. Bejan, V. Badescu, A. De Vos, A., Constructal theory of economics, Applied . Energy. 67 (2000) 37-60. 
[9] A. Bejan, Optimal internal structure of volumes cooled by single phase forced and natural convection, J. Electron. Packaging, 125 (2003) 200-207.

[10] A. Bejan, Why university rankings do not change: education as a natural hierarchical flow architecture. Int. J Design Nature Ecodyn 2 (2007) 319-27.

[11] A. Bejan, Two hierarchies in science: the free flow of ideas and the academy. Int. J Design Nature Ecodyn, 4 (2009) 386-94.

[12] G. Weinerth, The constructal analysis of warfare. Int J Design Nature Ecodyn 5, (2010), 268-76.

[13] A. Bejan, J.H. Marden, Unifying constructal theory for scale effects in running, swimming and flying. J Exp Biol 209 (2006) 238-48.

[14] J.D. Charles, A. Bejan, The evolution of speed, size and shape in modern athletics. J Exp Biol 212 (2009) 2419-25.

[15] A. Bejan, E.C Jones, J.D. Charles, The evolution of speed in athletics: why the fastest runners are black and swimmers white. Int. J Design Nature Ecodyn 5 (2010) 199-211.

[16] A.H. Reis, A.F Miguel, M Aydin,. Constructal theory of flow architecture of the lungs. Med Phys. 31 (2004) 1135-40.

[17] A.F. Miguel, Constructal pattern formation in stony corals, bacterial colonies and plant roots under different hydrodynamics conditions. Theor Biol 242 (2006) 954-61.

[18] A. Nakayama, F. Kuwahara, W. Liu, A macroscopic model for counter-current bioheat transfer in a circulatory system. Journal of Porous Medium 122009 289-300.

[19] S. Quéré, Constructal theory of plate tectonics. Int J Design Nature Ecodyn 5 ( 2010) $242-53$.

[20] A.H. Reis, C. Gama, Sand size versus beachface slope-an explanation based on the constructal law. Geomorphology 114 (2010) 276-83. 
[21] T. Bello-Ochende, J.P. Meyer, A. Bejan, Constructal ducts with wrinkled entrances Int. J. Heat Mass Transfer, 52 (2009) 3628-3633.

[22] Y.S. Muzychka, Constructal design of forced convection cooled micro-channel heat sinks and exchangers, Int. J. Heat Mass Transfer, 48 (2005) 3119-3124.

[23] L.A.O. Rocha, E. Lorenzini, C. Biserni, Geometric optimization of shapes on the basis of Bejan's Constructal theory Int. Comm. Heat Mass Transfer, 32 (2005) 1281-1288.

[24] S.W. Kim, S. Lorente, A. Bejan, Vascularised Materials with Heating from One Side and Coolant Forced from the Other Side, Int. J. Heat Mass Transfer 50 (2007) 34983506.

[25] M.R. Salimpour, M. Sharifhasan, E. Shirani, Constructal optimization of the geometry of an array of micro-channels, Int. Comm. Heat Mass Transfer, 38 (2010) 93-99.

[26] O.T. Olakoyejo, T. Bello-Ochende, J.P. Meyer, Geometric optimisation of forced convection in a vascularised material, Proceedings of the $8^{\text {th }}$ International Conference on Heat Transfer, Fluid Mechanics and Thermodynamics, Pointe Aux Piments, Mauritius (2011) 666-674.

[27] A. Bejan, Y. Fautrelle, Constructal multi-scale structure for maximal heat transfer density, Acta Mech. 163 (2003) 39-49.

[28] R.S. Matos, J.V.C. Vargas, A. Bejan, Three-dimensional optimization of staggered finned circular and elliptic tubes in forced convection, Int. J. Heat Mass Transfer 44 (2000) 3953-3961.

[29] A.H. Reis, Constructal Theory - Complex flow structures in engineering and in Nature in III Conferência Nacional em Mecânica de Fluidos, Termodinâmica e Energia (MEFTE - BRAGANÇA 09), 2009, 1- 17.

[30] A. Bejan, S. Lorente, Design with Constructal Theory, Hoboken Wiley, 2008. 
[31] A.H. Reis, Constructal Theory: From Engineering to Physics and How Flow Systems Develop Shape and Structure, Applied Mechanics Reviews 59 (2006) 269-282.

[32] Y. Fan, L. Luo, Recent Applications of Advances In Microchannel Heat Exchangers And Multi-Scale Design Optimisation, Heat Transfer Engineering 29 (2008) 461-474.

[33] A. Yilmaz, O. Buyukalaca, T. Yilmaz, Optimum shape and dimensions of ducts for convective heat transfer in laminar flow at constant wall temperature, Int. J. Heat Mass Transfer, 43 (2000) 767-775.

[34] A. K. da Silva, S. Lorente, A. Bejan, Optimal distribution of discrete heat sources on a plate with laminar forced convection, International Int. J. Heat Mass Transfer 47 (2004) 2139-2148.

[35] T. Bello-Ochende, L. Liebenberg, J.P. Meyer, Constructal Cooling Channels for Micro-channel Heat Sinks, Int. J. Heat Mass Transfer 50 (2007) 4141-4150.

[36] L.A.O. Rocha, E. Lorenzini, C. Biserni, and Y. Cho, Constructal design of a cavity cooled by convection, Int. J. Des. Nat. Ecody., 5 (2010) 212-220.

[37] C. Biserni, L.A.O. Rocha G. Stanescu, and E. Lorenzini, Constructal H-shaped cavities according to Bejan's theory Int. J. Heat Mass Transfer 50 (2007) 2132-2138.

[38] Y. S. Muzychka, Constructal multi-scale design of compact micro-tube heat sinks and heat exchangers, Int J. Thermal Sciences 46 (2007) 245-252.

[39] A.H. Reis, A.F. Miguel, A. Bejan, Constructal Theory of Particle Agglomeration of Design of Air-cleaning Devices, Journal Physics D: Applied Physic 39 (2006) 30863096

[40] J.P., Meyer, Constructal law in technology, thermofluid and Energy Systems, and in design education, Phys life Rev., 8, (2011) 247-248.

[41] A. Bejan and S. Lorente, The constructal law and the evolution of design in nature. Phys Life Rev 8 (2011) 209-240. 
[42] T. Basak, The law of life: the bridge between physics and biology, Phys Life Rev 8 (2011) 249-252.

[43] A.F. Miguel, The physics principle of generation of flow configuration, Phys Life Rev 8 (2011) 243-244.

[44] L. A. O. Rocha, Constructal law: from law of physics to applications and conferences, Phys Life Rev 8 (2011) 245-246.

[45] G. Lorenzini and C. Biserni, The constructal law: from design in nature to social dynamics and wealth as physics, Phys Life Rev 8 (2011) 259-260.

[46] J.O. Tuhtan, Go with the flow: connecting energy demand, hydropower, and fish with constructal theory, Phys Life Rev 8 (2011) 253-254.

[47] L. Wang, Universality of design and its evolution: Lorente. Phys Life Rev. 8 (2011) $257-258$

[48] Y. Ventikos, The importance of the constructal framework in understanding and eventually replicating structure in tissue, Phys Life Rev 8 (2011) 241-242.

[49] W-P. Ma, S-C Tzeng, and W-J Jwo, Flow resistance and forced convective heat transfer effects for various flow orientations in a packed channel, Int. Comm. Heat Mass Transfer 33 (2006) 319-326

[50] X-Q Wang, A. S. Mujumdar, C. Yap, Effect of orientation for phase change material (PCM)-based heat sinks for transient thermal management of electric components, Int. Comm. Heat Mass Transfer 34 (2007) 801-808.

[51] R-T Huang, W-J Sheu, C-C Wang, Orientation effect on natural convective performance of square pin fin heat sinks, Int. J. Heat Mass Transfer 51 (2008) 23682376. 
[52] H. Zhang, I. Mudawar, M. M. Hasan, Experimental and theoretical study of orientation effects on flow boiling CHF, Int. J. Heat Mass Transfer 45 (2002) 44634477.

[53] A. Tandiroglu, Effect of flow geometry parameters on transient heat transfer for turbulent flow in a circular tube with baffle inserts, Int. J. Heat Mass Transfer 49 (2006) $1559-1567$.

[54] P. Dutta, S. Dutta, Effect of baffle size, perforation, and orientation on internal heat transfer enhancement, Int. J. Heat Mass Transfer 41 (1998) 3005-3013.

[55] R.C. Chu, Thermal management roadmap cooling electronic products from handheld device to supercomputers, Proc. MIT Rohsenow Symposium, Cambridge, MA, 2002.

[56] SEMATECH, The National Technology Roadmap for Semiconductors: Technology, Need SEMATECH, Austin TX, 1997.

[57] S. Bhattacharjee, W.L. Grosshandler, The formation of wall jet near a high temperature wall under microgravity environment, ASME HTD 96, (1998) 711-716.

[58] S. Petrescu, Comments on the optimal spacing of parallel plates cooled by forced convection, Int. J. Heat Mass Transfer 37 (1994) 1283.

[59] Fluent Inc., Fluent Version 6 Manuals, Centerra Resource Park, 10 Cavendish Court, Lebanon, New Hampshire, USA, 2001 (www.fluent.com).

[60] S.V. Patankar, Numerical Heat Transfer and Fluid flow, Hemisphere, New York. 1980

[61] Fluent Inc., Gambit Version 6 Manuals, Centerra Resource Park, 10 Cavendish Court, Lebanon, New Hampshire, USA, 2001 (www.fluent.com).

[62] The MathWorks, Inc., MATLAB \& Simulink Release Notes for R2008a, 3 Apple Hill Drive, Natick, MA, 2008 (www.mathworks.com).

[63] F.M. White, Viscous Fluid Flow, 2nd Edition, McGraw-Hill International Editions, Singapore, 1991. 
[64] J.A. Snyman, A.M. Hay, The DYNAMIC-Q Optimization Method: An alternative to SQP? Computer and Mathematics with Applications 44 (2002) 1589-1598.

[65] J.A. Snyman, Practical Mathematical Optimisation: An Introduction to Basic Optimisation Theory and Classical and New Gradient-Based Algorithms, Springer, New York, 2005.

[66] J.A. Snyman, N. Stander, W.J. Roux, dynamic penalty function method for the solution of structural optimization problems, Appl. Math. Model. 18 (1994) 453-460.

[67] J.A. Visser, D.J. de Kock, Optimization Of Heat Sink Mass Using The DYNAMICQ Numerical Optimization Method, Comm. Nume. Methods in Engg. 18 (2002) 721727.

[68] T. Bello-Ochende, J.P. Meyer, F.U. Ighalo, Combined Numerical Optimization and Constructal Theory for the Design of Microchannel Heat Sinks, Numerical Heat Transfer, Part A, 58 (2010) 882-899.

[69] O.T. Olakoyejo, T. Bello-Ochende, J.P. Meyer, Mathematical optimisation of laminar forced convection heat transfer through a vascularised solid with square channels, Int. J. Heat Mass Transfer 55 (2012) 2402-2411.

[70] O.T. Olakoyejo, T. Bello-Ochende, J.P Meyer, Constructal conjugate cooling channels with internal heat generation, Int. J. Heat Mass Transfer 55 (2012) 4385-4396. 


\section{List of Figures}

Figure 1 Three-dimensional parallel circular of (a) PF-1, (b) CF-2 and (c) CF-3 orietations.

Figure 2 The boundary conditions of the three-dimensional computational domain of the elemental volume of (a) PF-1, (b) CF-2 and (c) CF-3 orietations

Figure 3 A section of the discretised 3-D computational domain of the elemental solid-fluid volume considered for the simulation

Figure 4 Flow chart of numerical simulation

Figure 5 Effect of optimised dimensionless hydraulic diameter $d_{h}$ on the peak temperature at $\Delta P=50 \mathrm{kPa}$

Figure 6 Effect of optimised elemental volume on the peak temperature at $\Delta \mathrm{P}=50 \mathrm{kPa}$

Figure 7 Effect of dimensionless pressure difference on the minimised dimensionless global thermal resistance

Figure 8 The effect of dimensionless pressure difference on the optimised hydraulic diameter

Figure 9 The effect of dimensionless pressure difference on the optimised spacing 


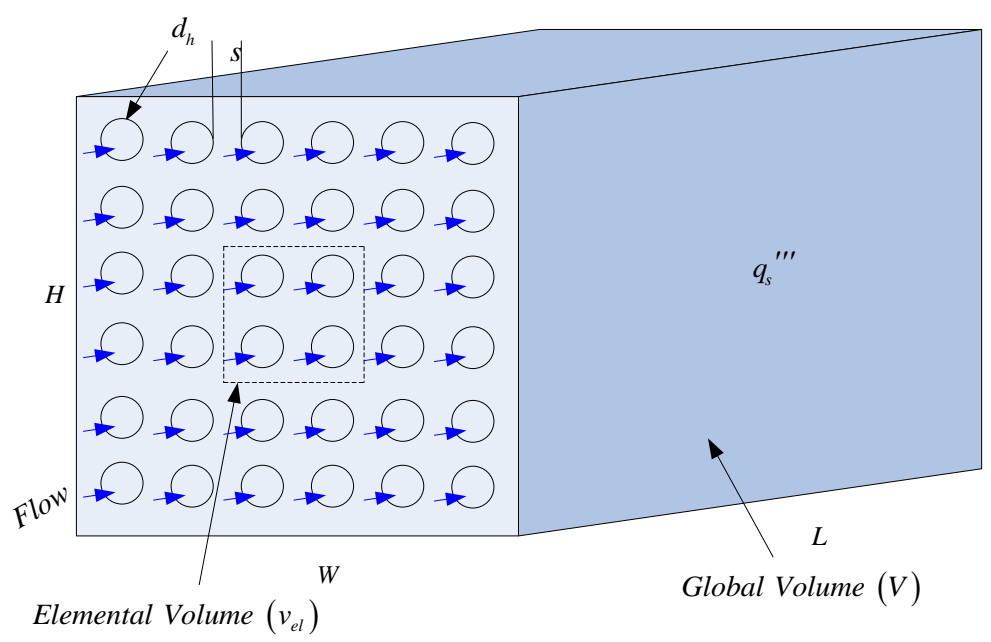

(a)

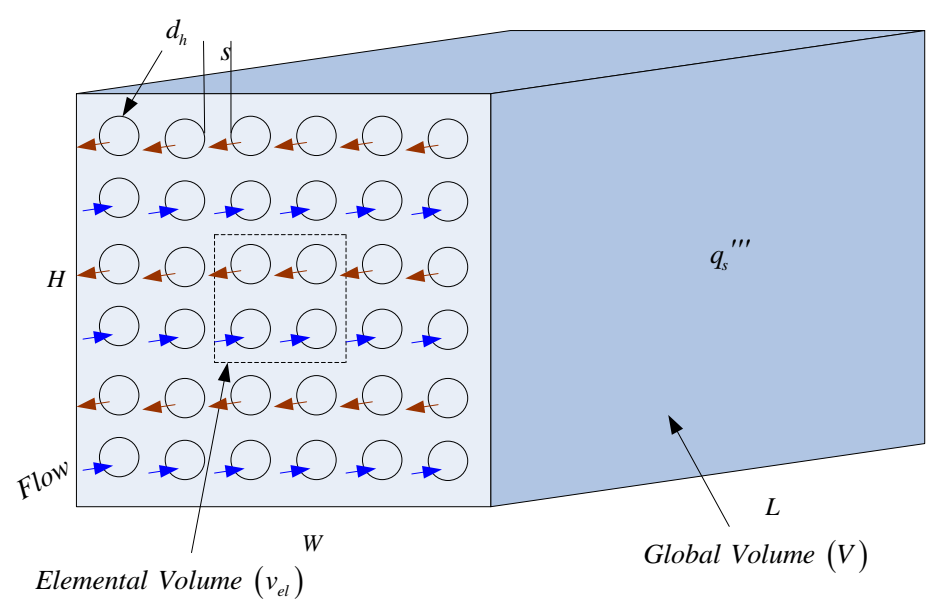

(b)

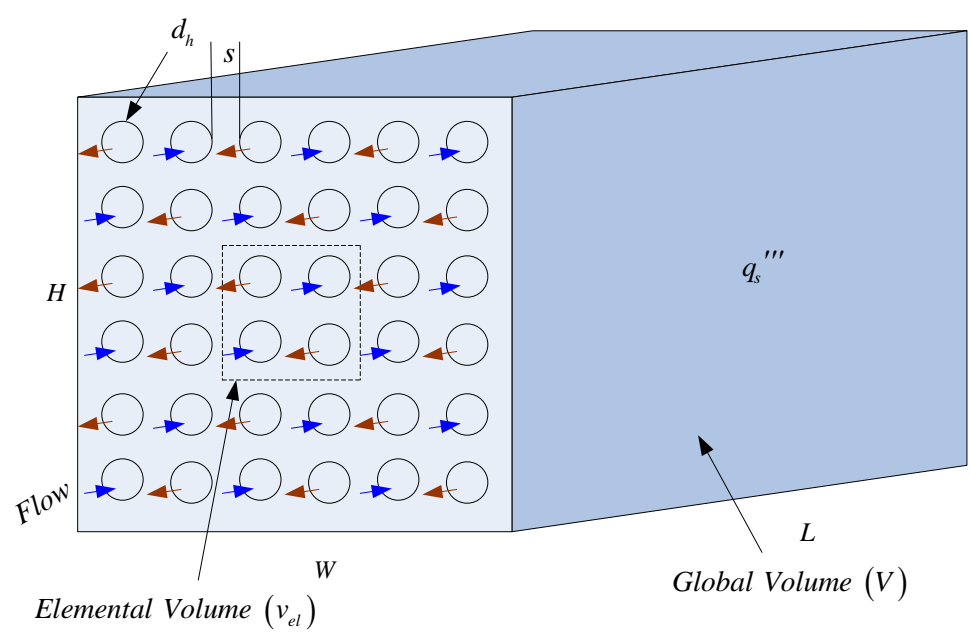

(c)

Figure 1 Three-dimensional parallel circular of (a) PF-1, (b) CF-2 and (c) CF-3 orietations. 


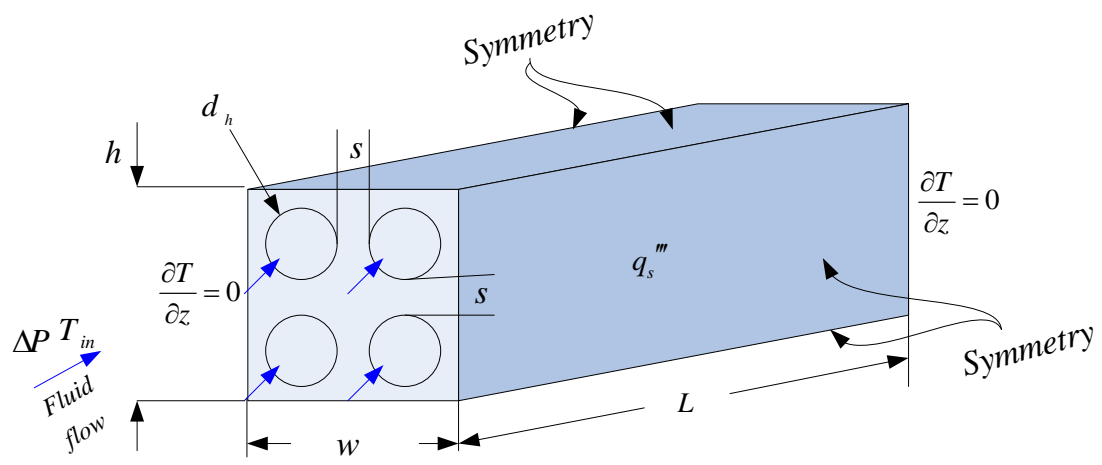

(a)

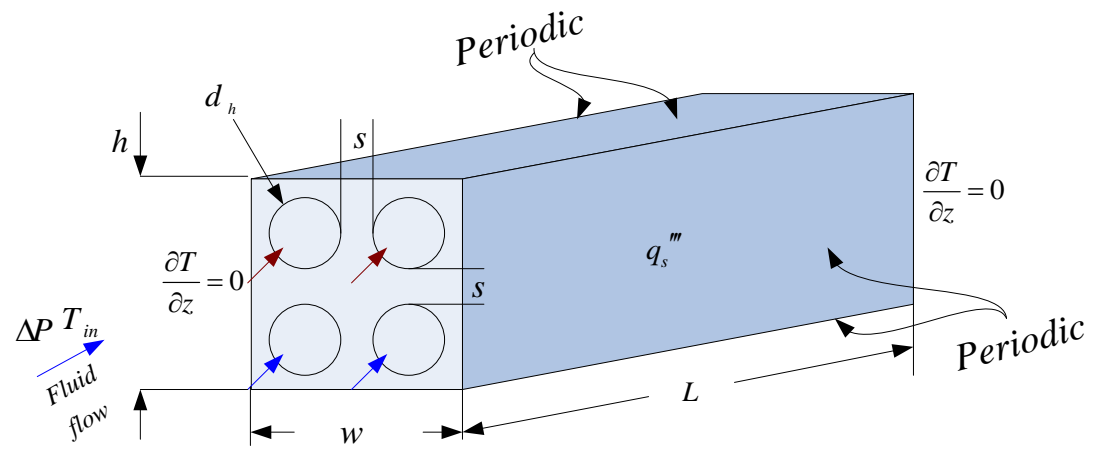

(b)

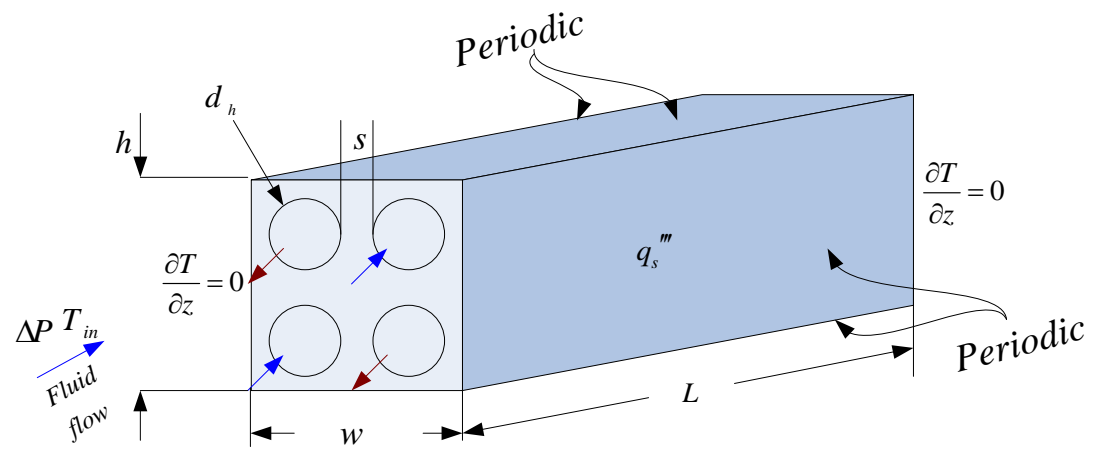

(c)

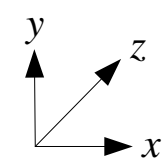

Figure 2 The boundary conditions of the three-dimensional computational domain of the 
elemental volume of (a) PF-1, (b) CF-2 and (c) CF-3 orietations.

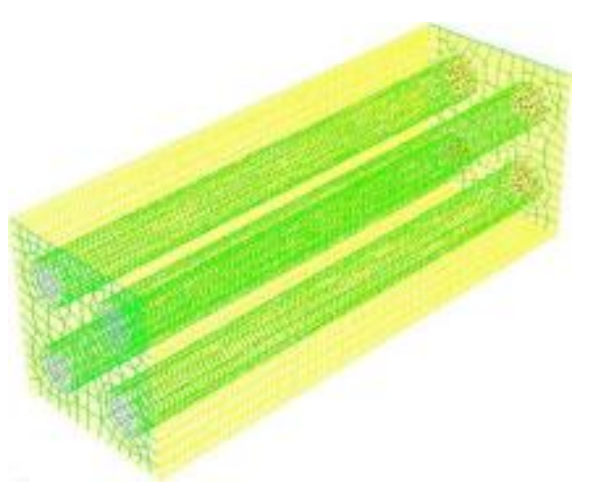

(a)

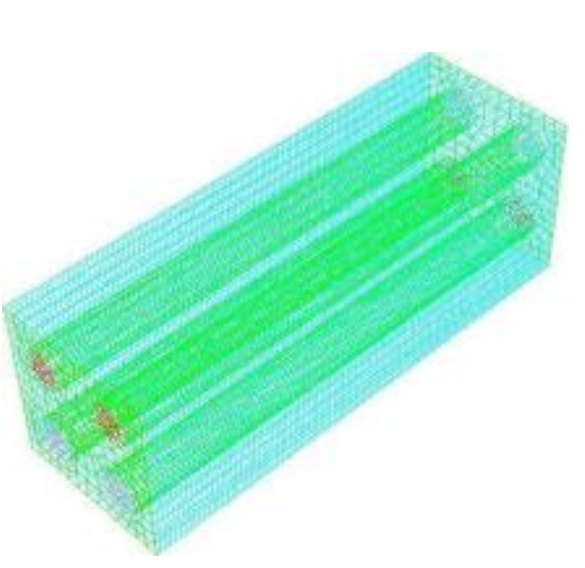

(b) 


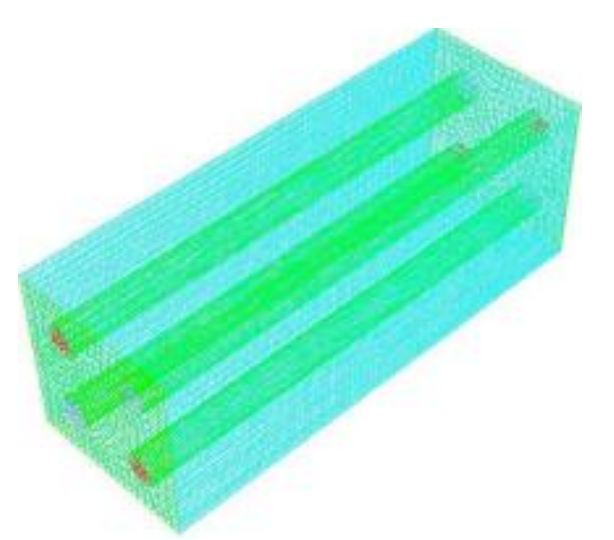

(c)

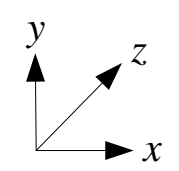

Figure 3 The discretised 3-D computational domains of (a) PF-1, (b) CF-2 and (c) CF-3 orietations. 


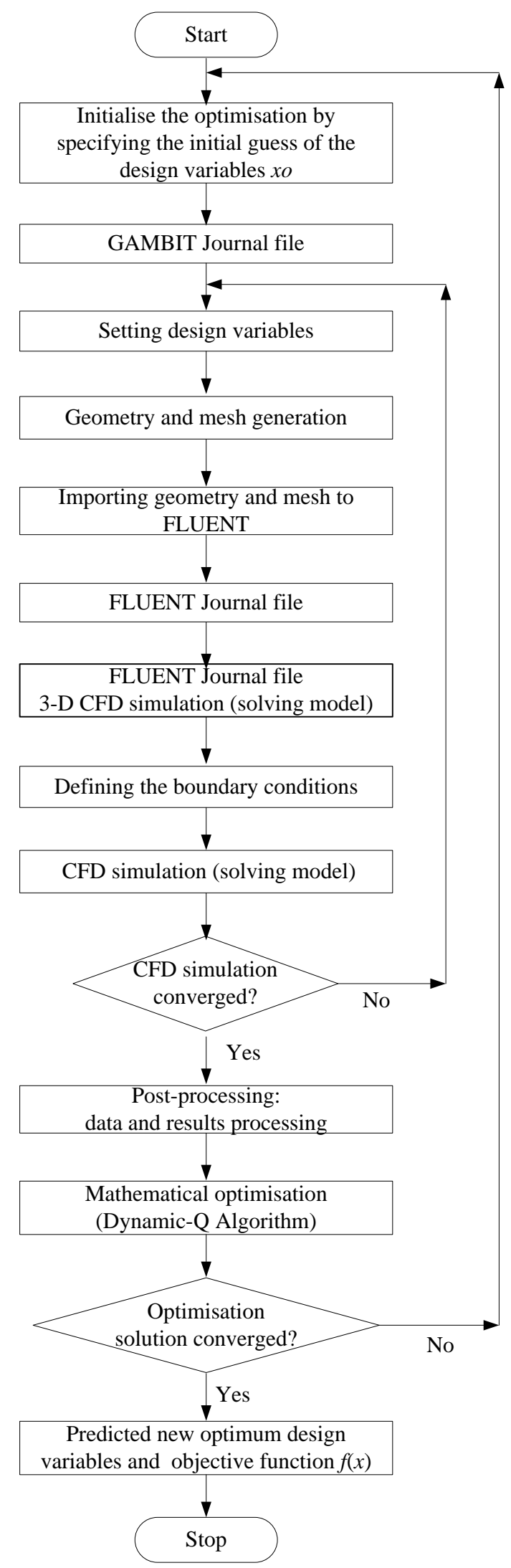

Figure 4 Flow chart of numerical simulation. 


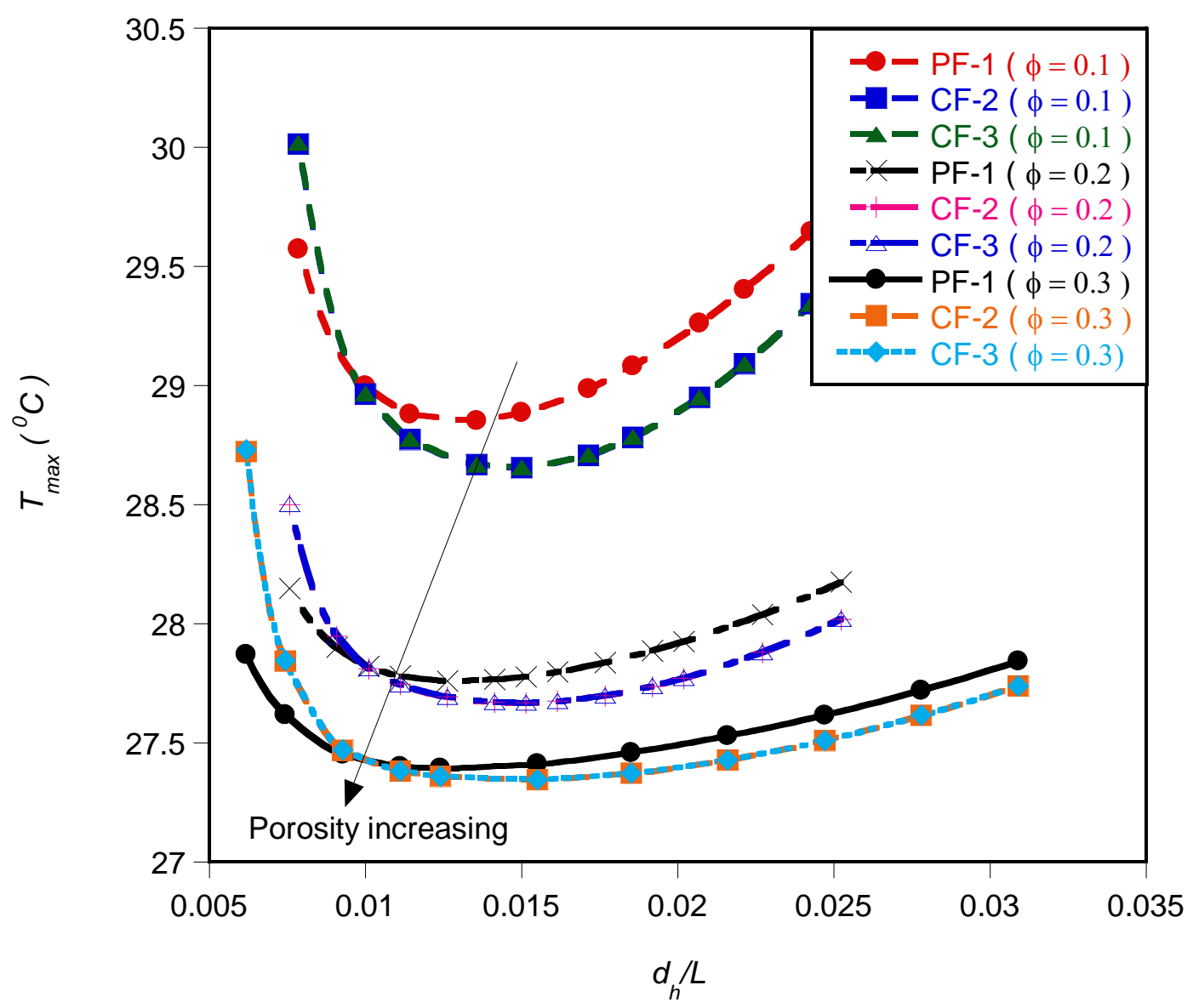

Figure 5 Effect of optimised dimensionless hydraulic diameter $d_{h}$ on the peak temperature at $\Delta P=50 \mathrm{kPa}$. 


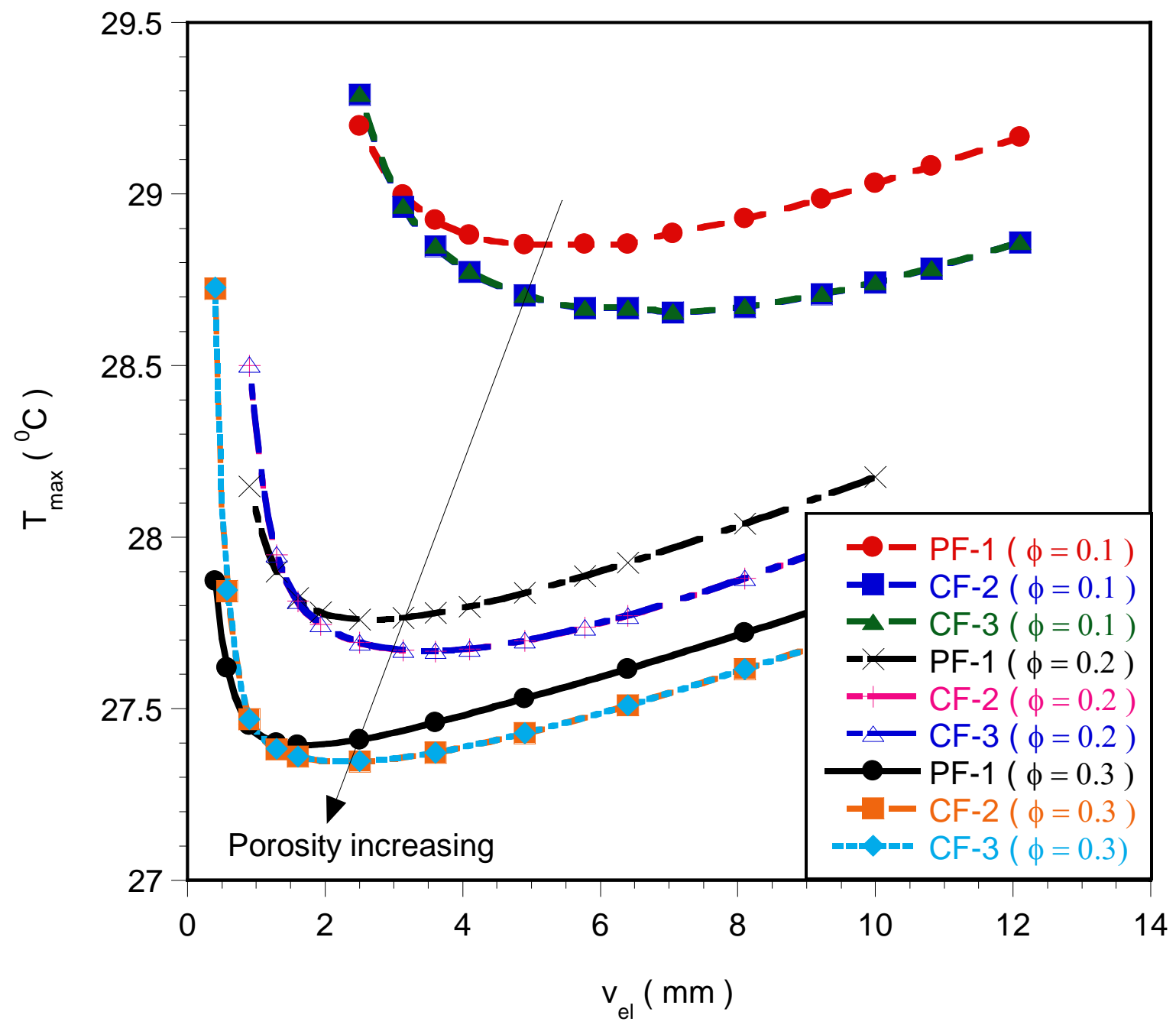

Figure 6 Effect of optimised elemental volume on the peak temperature at $\Delta \mathrm{P}=50 \mathrm{kPa}$. 


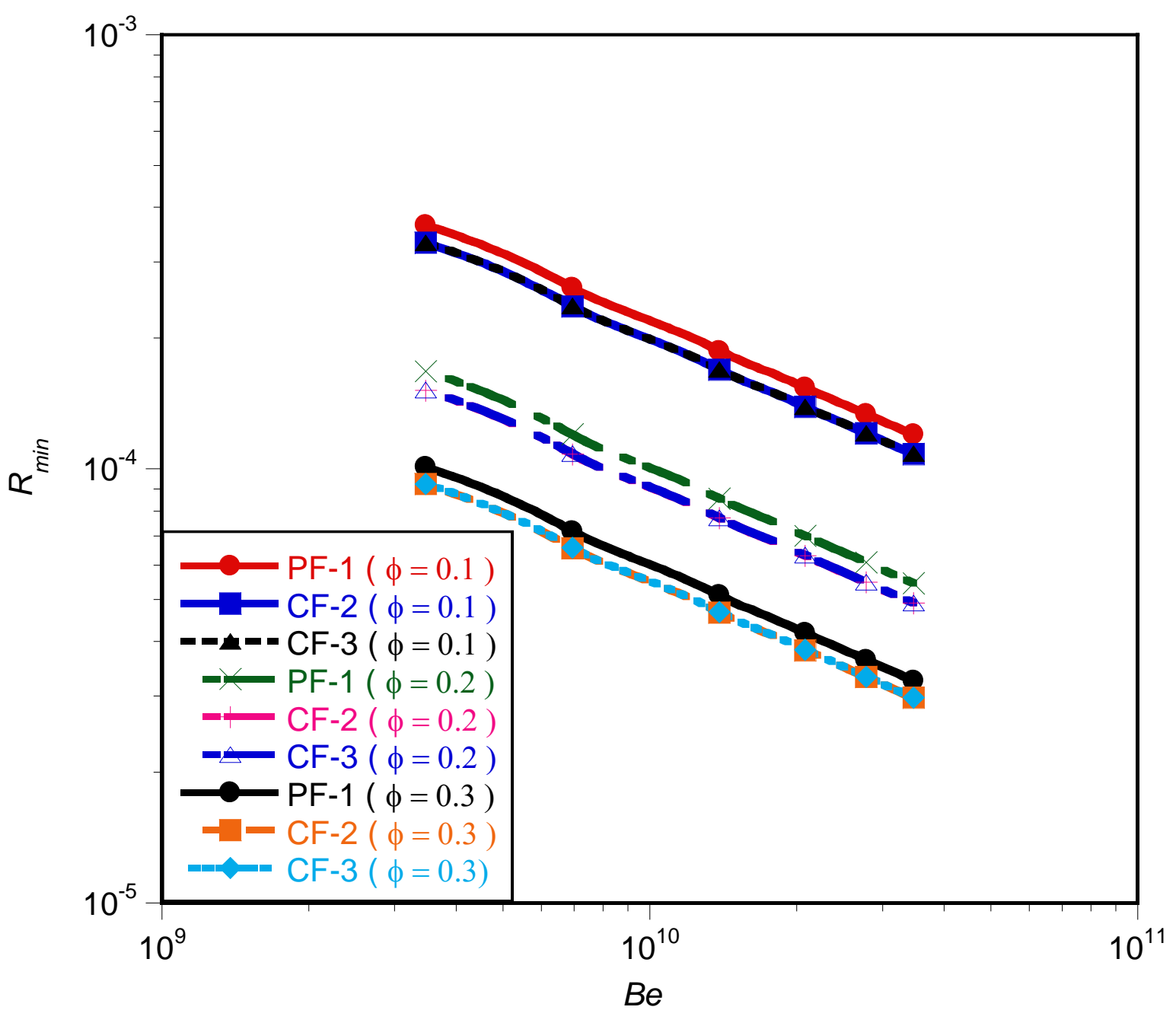

Figure 7 Effect of dimensionless pressure difference on the minimised dimensionless global thermal resistance. 


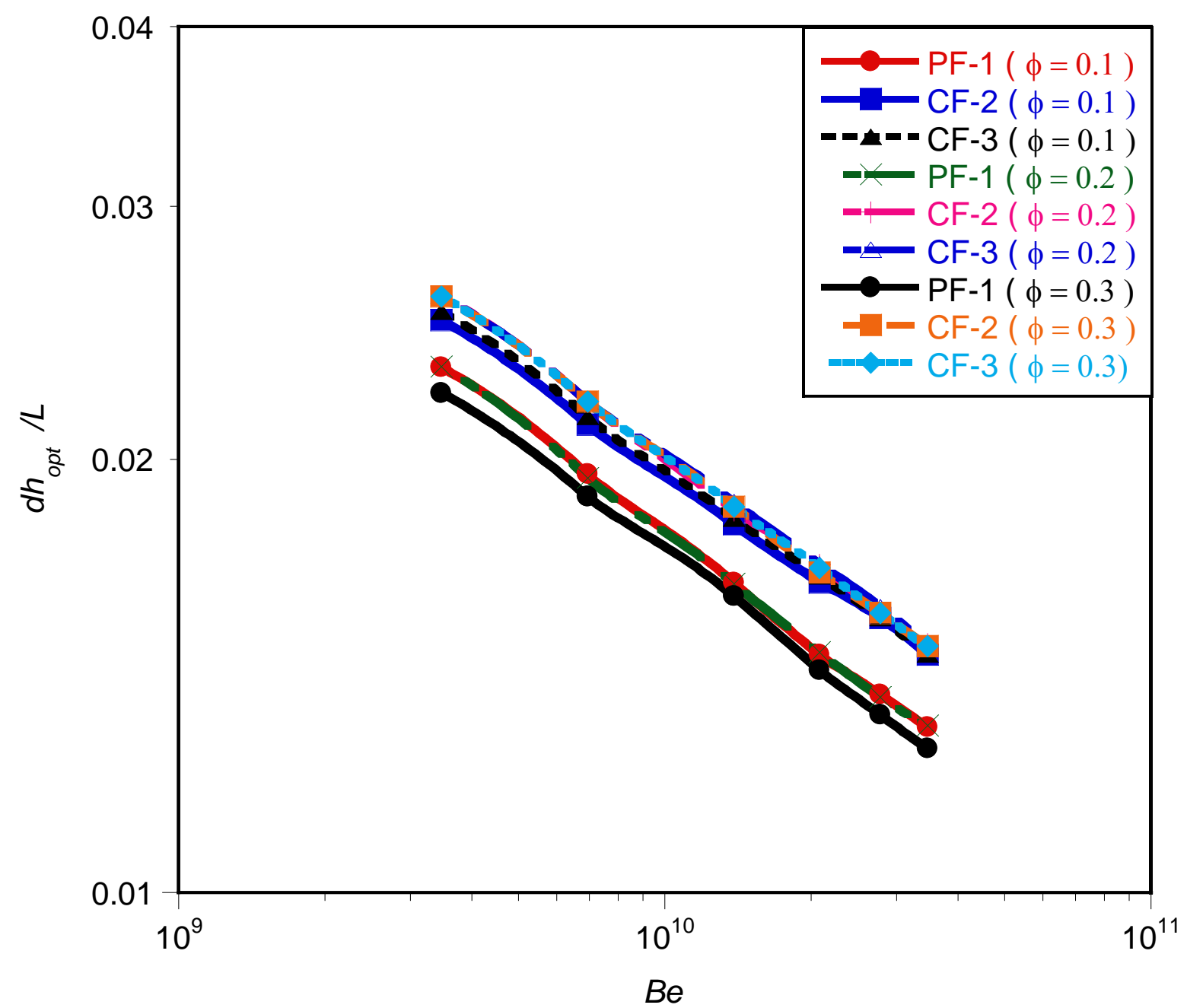

Figure 8 The effect of dimensionless pressure difference on the optimised hydraulic diameter. 


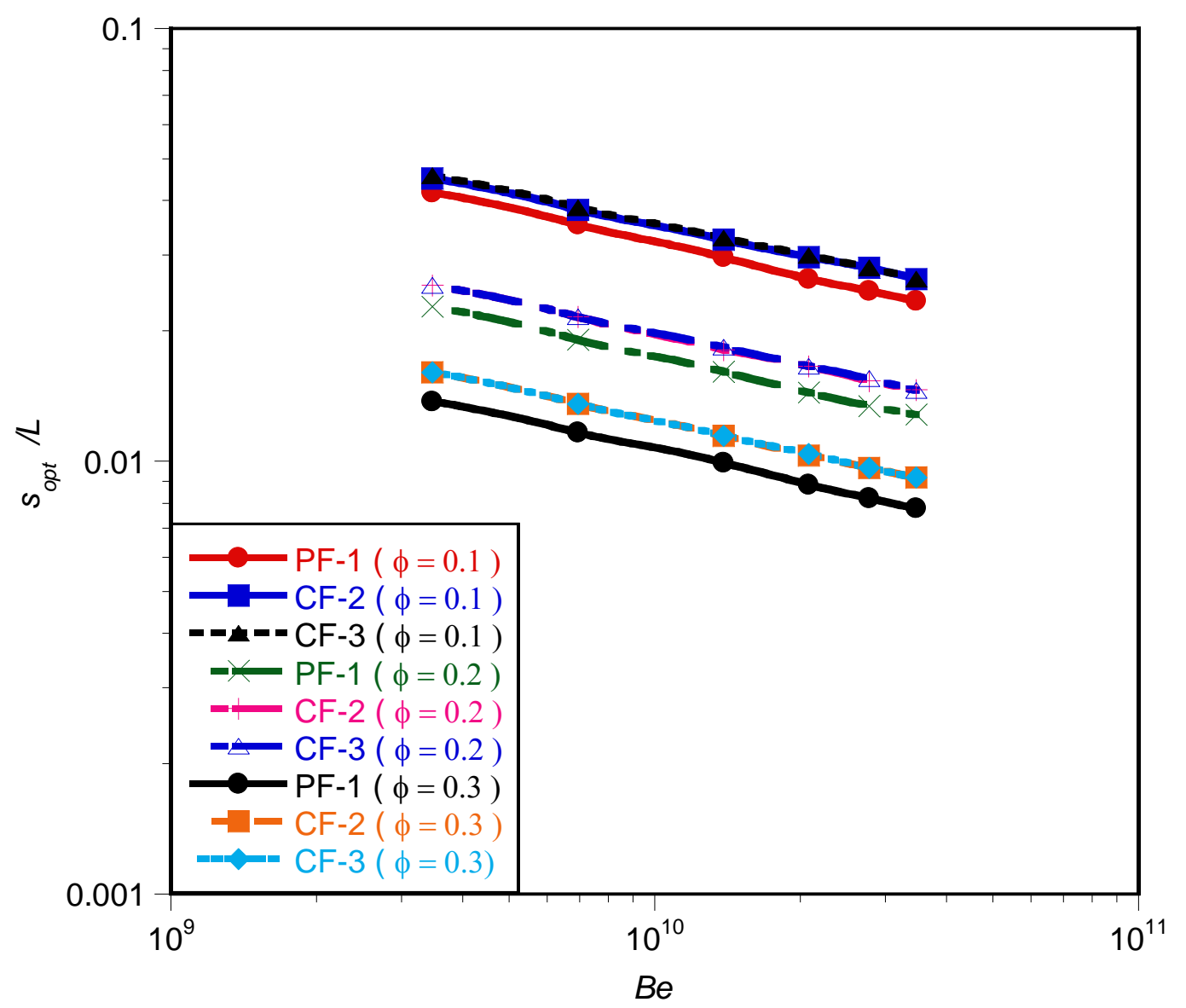

Figure 9 The effect of dimensionless pressure difference on the optimised spacing. 